\title{
Multi Objective Dispatch Problem with Valve Point Effect Loading of Fuel Cost and Emission Criterion
}

\author{
S. Krishnamurthy and R. Tzoneva
}

\begin{abstract}
In most of the publications the dispatch problem is formulated using fuel cost and emission function without considering valve point effect. The paper formulates a multi objective dispatch problem with valve point effect considered in both fuel cost and emission function. Most of the literature uses penalty factors such as Max-Max, Min-Min, Average, and common to combine both fuel cost and emission function in one criterion. In addition to this, Max-Min and, MinMax penalty factors are proposed in the paper. Lagrange's method is formulated to solve the combined economic emission dispatch problem with proposed penalty factors. The considered dispatch problem is solved for the IEEE test system of five generators by using Matlab software. The results show that Min-Max penalty factor method gives minimum fuel cost and emission values in comparison to other penalty factors.
\end{abstract}

Index Terms-Power system optimization, economic dispatch, multi objective dispatch problem, penalty factors, valve point effect loading, and lagrange's method.

\section{INTRODUCTION}

Optimization of the power system plays a major role in thermal power plants energy production. The challenges of the engineers are to optimize the real power of the generator and to minimize the fuel cost and emission of the power plant. Most of the literature papers concentrate on combined economic emission dispatch problem without considering valve point effect loading. Actually the power plant has multiple steam valves, so it is necessary to consider the valve point effect loading. Therefore solution of the dispatch problem is also more accurate when the dispatch problem with valve point effect loading is solved. The methods used or developed to solve the multi objective dispatch problems formulated by using penalty factors are described in the paper. .The combined fuel cost function and emission function without valve point effect is formulated by Weighted Sum Method (WSM) using PSO algorithm in [17], [18] and Evolutionary programming in [19].The combined fuel cost function and emission function without valve point effect is formulated by various price penalty factors approaches using recursive algorithm in [20]. MaxMax price penalty factor method using quadratic programming in [21], security constrained unit commitment

Manuscript received September 3, 2012; revised October 4, 2012.

The authors are with the Department of Electrical Engineering, Cape Peninsula University of Technology, Bellville, South Africa - 7535 (email: ksenthilvpm@gmail.com) problem algorithm in [22], sequential approach with matrix frame work in [23], PSO in [24], Improved back propagation neural network in [25], and Lagrange's method in [26]. The combined fuel cost function without valve point effect and emission function with valve point effect is formulated using PSO algorithm in [15]. The combined fuel cost function with valve point effect and emission function with valve point effect is formulated using Improved PSO algorithm with carbon tax considered in [14], Improved pattern search in [16] using WSM method, and Lagrange's method in [27]. Most of the literature papers reported that the multi objective dispatch problem is solved using the WSM and Max-Max penalty factors. The paper proposes two penalty factors Min-Max and Max-Min in order to solve the multi-criteria dispatch problem with or without valve point effect as described by equation (5) and (14) respectively. The optimization problem is solved on the basis of the Lagrange's method. The paper consists of five parts. Part 1 describes the introduction of the dispatch problem, economic dispatch problem formulation is presented in part 2, part 3 covers Lagrange's method for multi-criteria dispatch problem, simulation results and conclusion are given in part 4 and part 5 respectively.

\section{ECONOMIC DisPATCH PROBLEM FORMULATION}

\section{A. Fuel Cost Function}

The fuel cost of the economic dispatch problem can be formulated as

$$
F_{C}=\sum_{i=1}^{n} F_{i}\left(P_{i}\right)=\sum_{i=1}^{n}\left(a_{i} P_{i}^{2}+b_{i} P_{i}+c_{i}\right) \quad[\$ / h r]
$$

where

$F_{C} \quad$ - Total Fuel Cost

$F_{i}\left(P_{i}\right)$ - Fuel cost of the $\mathrm{i}^{\text {th }}$ generator

$P_{i} \quad$ - Real power generation of unit i

$a_{i}, b_{i}, c_{i}$ - Cost coefficients of generating for unit $\mathrm{i}$

$\mathrm{n} \quad$ - Number of generating units

Thermal power plants have multiple steam valves. To accurately evaluate the fuel cost function, the valve point effect loading is considered as follows:

$$
F_{C V P}=\sum_{i=1}^{n} F_{i}\left(P_{i}\right)=\sum_{i=1}^{n}\left[\begin{array}{l}
\left(a_{i} P_{i}^{2}+b_{i} P_{i}+c_{i}\right) \\
+\left|e_{i} \sin \left(f_{i}\left(P_{i, \min }-P_{i}\right)\right)\right|
\end{array}\right][\$ / h r]
$$

where

$F_{C V P}$ - Total Fuel Cost with valve point effect

$e_{i}, f \quad$ Valve point effect cost coefficients of generating 
unit $i$

\section{B. Emission Function}

The emission of the thermal power plant can be formulated as a second order polynomial function as

$$
E_{T}=\sum_{i=1}^{n}\left(\alpha_{i} P_{i}^{2}+\beta_{i} P_{i}+\gamma_{i}\right)[K g / h r]
$$

where

$\mathrm{E}_{\mathrm{T}}-$ Total emission

$\alpha_{i}, \beta_{i}, \gamma_{i}$ - Emission coefficients of generating unit $\mathrm{i}$

The emission equation (3) can be formulated with inserting the valve point effect as follows:

$$
E_{T V P}=\sum_{i=1}^{n}+\begin{aligned}
& \left(\alpha_{i} P_{i}^{2}+\beta_{i} P_{i}+\gamma_{i}\right)+ \\
& +\left|\delta_{i} \sin \left(\eta_{i}\left(P_{i, \min }-P_{i}\right)\right)\right|
\end{aligned} \quad[K g / h r]
$$

where

$\mathrm{E}_{\mathrm{TVP}}$ Total emission with valve point effect

$\delta_{i}, \eta_{i}$ Valve point effect emission coefficients of generating unit $\mathrm{i}$

\section{Multi-Criteria Objective Function without Valve Point Effect Loading Using Penalty Factors}

The combined economic emission dispatch problem is formulated as follows:

$$
F_{T}=\sum_{i=1}^{n}\left[\left(a_{i} P_{i}^{2}+b_{i} P_{i}+c_{i}\right)+h_{i}\left(\alpha_{i} P_{i}^{2}+\beta_{i} P_{i}+\gamma_{i}\right)\right]
$$

$[\$ / h r]$

where

$$
h_{i} \text { - Price penalty factor }
$$

\section{Formulation of Price Penalty Factors of Multi-Criteria Dispatch Problem without Valve Point Effect}

The fuel cost and emission function are correlated with any one of the following price penalty factors. The paper uses six types of penalty factor for the multi-criteria dispatch problem, as follows:

The ratio of minimum fuel cost and maximum emission is called Min-Max Penalty factor [26], [27]. It can be formulated as

$$
h_{i}=\frac{\left(a_{i} P_{i, \min }^{2}+b_{i} P_{i, \min }+c_{i}\right)}{\left(\alpha_{i} P_{i, \max }^{2}+\beta_{i} P_{i, \max }+\gamma_{i}\right)}[\$ / k g]
$$

The ratio of maximum fuel cost and maximum emission is called Max- Max Penalty factor [20] to [25]. It can be formulated as

$$
h_{i}=\frac{\left(a_{i} P_{i, \text { max }}^{2}+b_{i} P_{i, \text { max }}+c_{i}\right)}{\left(\alpha_{i} P_{i, \max }^{2}+\beta_{i} P_{i, \max }+\gamma_{i}\right)} \quad[\$ / k g]
$$

The ratio of minimum fuel cost and minimum emission is called Min- Min Penalty factor [20]. It can be formulated as

$$
h_{i}=\frac{\left(a_{i} P_{i, \min }^{2}+b_{i} P_{i, \min }+c_{i}\right)}{\left(\alpha_{i} P_{i, \min }^{2}+\beta_{i} P_{i, \min }+\gamma_{i}\right)}[\$ / k g]
$$

The ratio of maximum fuel cost and minimum emission is called Max- Min Penalty factor [26], [27]. It can be formulated as

$$
h_{i}=\frac{\left(a_{i} P_{i, \max }^{2}+b_{i} P_{i, \max }+c_{i}\right)}{\left(\alpha_{i} P_{i, \text { min }}^{2}+\beta_{i} P_{i, \min }+\gamma_{i}\right)}[\$ / \mathrm{kg}]
$$

The average of the Min-Max, Max-Max, Min-Min, and Max-Min is called the average penalty factor [20]. It can be formulated as

$$
h_{i}=\frac{\left[\begin{array}{l}
\frac{\left(a_{i} P_{i, \text { min }}{ }^{2}+b_{i} P_{i, \text { min }}+c_{i}\right)}{\left(\alpha_{i} P_{i, \max }^{2}+\beta_{i} P_{i, \max }+\gamma_{i}\right)}+\frac{\left(a_{i} P_{i, \max }{ }^{2}+b_{i} P_{i, \text { max }}+c_{i}\right)}{\left(\alpha_{i} P_{i, \text { max }}^{2}+\beta_{i} P_{i, \text { max }}+\gamma_{i}\right)}+ \\
+\frac{\left(a_{i} P_{i, \text { min }}{ }^{2}+b_{i} P_{i, \min }+c_{i}\right)}{\left(\alpha_{i} P_{i, \text { min }}^{2}+\beta_{i} P_{i, \text { min }}+\gamma_{i}\right)}+\frac{\left(a_{i} P_{i, \text { max }}{ }^{2}+b_{i i, \max }+c_{i}\right)}{\left(\alpha_{i} P_{i, \text { min }}^{2}+\beta_{i} P_{i, \text { min }}+\gamma_{i}\right)}
\end{array}\right]}{4}[\$ / k g]
$$

Apart from the penalty factors discussed above, a common penalty factor [20] exists for the multi-criteria dispatch problem. It can be formulated as follows

$$
h_{i}=\frac{\sum_{i=1}^{n} \frac{\left[\begin{array}{c}
\frac{\left(a_{i} P_{i, \text { min }}{ }^{2}+b_{i} P_{i, \text { min }}+c_{i}\right)}{\left(\alpha_{i} P_{i, \text { max }}^{2}+\beta_{i} P_{i, \text { max }}+\gamma_{i}\right)}+\frac{\left(a_{i} P_{i, \text { max }}{ }^{2}+b_{i} P_{i, \text { max }}+c_{i}\right)}{\left(\alpha_{i} P_{i, \text { max }}^{2}+\beta_{i} P_{i, \text { max }}+\gamma_{i}\right)}+ \\
+\frac{\left(a_{i} P_{i, \text { min }}{ }^{2}+b_{i} P_{i, \text { min }}+c_{i}\right)}{\left(\alpha_{i} P_{i, \text { min }}^{2}+\beta_{i} P_{i, \text { min }}+\gamma_{i}\right)}+\frac{\left(a_{i} P_{i, \text { max }}{ }^{2}+b_{i i, \max }+c_{i}\right)}{\left(\alpha_{i} P_{i, \text { min }}^{2}+\beta_{i} P_{i, \text { min }}+\gamma_{i}\right)}
\end{array}\right]}{4}}{n}
$$

$[\$ / k g]$

E. Multi-Criteria Objective Function with Valve Point Effect Loading Using Penalty Factors

A couple of cases can be considered:

Fuel cost function with valve point effect loading and emission function without valve point effect:

$$
F_{T}=\sum_{i=1}^{n}\left[\begin{array}{l}
\left(\left(a_{i} P_{i}^{2}+b_{i} P_{i}+c_{i}\right)+\mid e_{i} \sin \left(f_{i}\left(P_{i \min }-P_{i}\right) \mid\right)+\right. \\
+h_{i}\left(\alpha_{i} P_{i}^{2}+\beta_{i} P_{i}+\gamma_{i}\right)
\end{array}\right]
$$

[\$/hr]

Fuel cost function without valve point effect loading and emission function with valve point effect:

$$
F_{T}=\sum_{i=1}^{n}\left[\left(a_{i} P_{i}^{2}+b_{i} P_{i}+c_{i}\right)+h_{i}\left(\begin{array}{l}
\left(\alpha_{i} P_{i}^{2}+\beta_{i} P_{i}+\gamma_{i}\right)+ \\
+\left|\delta_{i} \sin \left(\eta_{i}\left(P_{i \min }-P_{i}\right)\right)\right|
\end{array}\right)\right]
$$

[\$/hr]

Fuel cost function and emission function with valve point effects:

$$
F_{T V P}=\sum_{i=1}^{n}\left[\begin{array}{l}
\left(\left(a_{i} P_{i}^{2}+b_{i} P_{i}+c_{i}\right)+\left|e_{i} \sin \left(f_{i}\left(P_{\text {min }}-P_{i}\right)\right)\right|\right)+ \\
+h_{i}\left(\begin{array}{l}
\left(\alpha_{i} P_{i}^{2}+\beta_{i} P_{i}+\gamma_{i}\right)+ \\
+\left|\delta_{i} \sin \left(\eta_{i}\left(P_{i \min }-P_{i}\right)\right)\right|
\end{array}\right)
\end{array}\right]
$$

\section{F. Formulation of Price Penalty Factors of Multi-Criteria} Dispatch Problem with Valve Point Effect

The fuel cost and emission functions with valve point effect are correlated with any one of the following price penalty factors. The paper uses six types of penalty factors 
for the multi-criteria dispatch problem as follows:

The ratio of minimum fuel cost and maximum emission with valve point effect is called Min-Max Penalty factor. It can be formulated as

$$
h_{i}=\frac{\left(a_{i} P_{i, \text { min }}^{2}+b_{i} P_{i, \text { min }}+c_{i}\right)+\left|e_{i} \sin \left(f_{i}\left(P_{i, \text { min }}-P_{i, \min }\right)\right)\right|}{\left(\alpha_{i} P_{i, \text { max }}^{2}+\beta_{i} P_{i, \text { max }}+\gamma_{i}\right)+\mid \delta_{i} \sin \left(\eta_{i}\left(P_{i, \text { max }}-P_{i, \text { max }}\right) \mid\right.}[\$ / k g]
$$

The ratio of maximum fuel cost and maximum emission with valve point effect is called Max- Max Penalty factor. It can be formulated as

$$
h_{i}=\frac{\left(a_{i} P_{i, \text { max }}^{2}+b_{i} P_{i, \text { max }}+c_{i}\right)+\left|e_{i} \sin \left(f_{i}\left(P_{i, \max }-P_{i, \text { max }}\right)\right)\right|}{\left(\alpha_{i} P_{i, \text { max }}^{2}+\beta_{i} P_{i, \text { max }}+\gamma_{i}\right)+\left|\delta_{i} \sin \left(\eta_{i}\left(P_{i, \text { max }}-P_{i, \max }\right)\right)\right|} \quad[\$ / k g]
$$

The ratio of minimum fuel cost and minimum emission with valve point effect is called Min- Min Penalty factor. It can be formulated as

$$
h_{i}=\frac{\left(a_{i} P_{i, \text { min }}{ }^{2}+b_{i} P_{i, \text { min }}+c_{i}\right)+\left|e_{i} \sin \left(f_{i}\left(P_{i, \text { min }}-P_{i, \text { min }}\right)\right)\right|}{\left(\alpha_{i} P_{i, \text { min }}^{2}+\beta_{i} P_{i, \text { min }}+\gamma_{i}\right)+\mid \delta_{i} \sin \left(\eta_{i}\left(P_{i, \text { min }}-P_{i, \text { min }}\right) \mid\right.}[\$ / k g]
$$

The ratio of maximum fuel cost and minimum emission with valve point effect is called Max- Min Penalty factor. It can be formulated as

$$
h_{i}=\frac{\left(a_{i} P_{i, \text { max }}^{2}+b_{i} P_{i, \text { max }}+c_{i}\right)+\mid e_{i} \sin \left(f_{i}\left(P_{i, \text { max }}-P_{i, \text { max }}\right) \mid\right.}{\left(\alpha_{i} P_{i, \text { min }}^{2}+\beta_{i} P_{i, \text { min }}+\gamma_{i}\right)+\mid \delta_{i} \sin \left(\eta_{i}\left(P_{i, \text { min }}-P_{i, \text { min }}\right) \mid\right.}[\$ / k g]
$$

The average of the Min-Max, Max-Max, Min-Min, and Max-Min with valve point effect is called the average penalty factor. It can be formulated as

$$
h_{i}=\frac{\left[\begin{array}{c}
\left(a_{i} P_{i, \text { min}}{ }^{2}+b_{i} P_{i, \text { min}}+c_{i}\right)+\left|e_{i} \sin \left(f_{i}\left(P_{i, \text { min }}-P_{i, \text { min }}\right)\right)\right| \\
\left(\alpha_{i} P_{i, \text { max }}^{2}+\beta_{i} P_{i, \text { max }}+\gamma_{i}\right)+\left|\delta_{i} \sin \left(\eta_{i}\left(P_{i, \text { max }}-P_{i, \text { max }}\right)\right)\right| \\
+\frac{\left(a_{i} P_{i, \text { max }}{ }^{2}+b_{i} P_{i, \text { max }}+c_{i}\right)+\mid e_{i} \sin \left(f_{i}\left(P_{i, \text { max }}-P_{i, \text { max }}\right) \mid\right.}{\left(\alpha_{i} P_{i, \text { max }}^{2}+\beta_{i} P_{i, \text { max }}+\gamma_{i}\right)+\left|\delta_{i} \sin \left(\eta_{i}\left(P_{i, \text { max }}-P_{i, \text { max }}\right)\right)\right|} \\
+\frac{\left(a_{i} P_{i, \text { min }}{ }^{2}+b_{i} P_{i, \text { min }}+c_{i}\right)+\left|e_{i} \sin \left(f_{i}\left(P_{i, \text { min }}-P_{i, \text { min }}\right)\right)\right|}{\left(\alpha_{i} P_{i, \text { min }}^{2}+\beta_{i} P_{i, \text { min }}+\gamma_{i}\right)+\mid \delta_{i} \sin \left(\eta_{i}\left(P_{i, \text { min }}-P_{i, \text { min }}\right) \mid\right.}+ \\
+\frac{\left(a_{i} P_{i, \text { max }}{ }^{2}+b_{i, \text { max }}+c_{i}\right)+\mid e_{i} \sin \left(f_{i}\left(P_{i, \text { max }}-P_{i, \text { max }}\right) \mid\right.}{\left(\alpha_{i} P_{i, \text { min }}^{2}+\beta_{i} P_{i, \text { min }}+\gamma_{i}\right)+\left|\delta_{i} \sin \left(\eta_{i}\left(P_{i, \text { min }}-P_{i, \text { min }}\right)\right)\right|}
\end{array}\right]}{4}
$$

Apart from the penalty factors discussed above, a common penalty factor exist for the multi-criteria dispatch problem. It can be formulated as follows

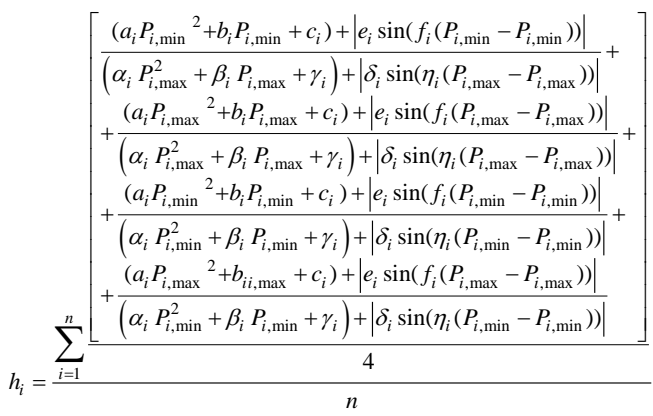

\section{G. Constraints of the Dispatch Problem}

The combined economic dispatch problems with criterion functions (5) and (14) are solved for every type of the price penalty factors (6) to (11) and (15) to (20) under the constraints:

\section{Power Balance Constraint}

$$
\sum_{i=1}^{n} P_{i}=P_{G}=P_{D} \quad[M W]
$$

where

$P_{G^{-}}$Total power generation of the system

$P_{D^{-}}$Total demand of the system

Generator operational limit constraints

$$
P_{i, \min } \leq P_{i} \leq P_{i, \max }, i=\overline{1, n}[M W]
$$

where

$P_{i, \min }$-Minimum value of real power allowed at generator $i$

$P_{i, \max }$-Maximum value of real power allowed at generator $i$

\section{Formulation of LagRAnge'S Method FOR Multi- CRITERIA DISPATCH PROBLEM}

\section{A. Multi-Criteria Dispatch Problem without Valve Point Effect Loading}

The objective function in this case, is described by equation (5). The optimization problem is to find the optimal active power $P_{i}, i=\overline{1, n}$ produced by the generators in such a way that the criterion (5) is minimized and the constraints (21), (22) are satisfied. The problem has to be solved for every one of the price penalty factors (6) to (11). The problem is solved using Lagrange's method by introduction of the Lagrange's variable $\lambda$ and formulation of a Lagrange's function:

$$
\begin{gathered}
L=F_{T}+\lambda\left(P_{D}-\sum_{i=1}^{n} P_{i}\right) \\
L=\sum_{i=1}^{n}\left[\begin{array}{l}
\left(a_{i} P_{i}^{2}+b_{i} P_{i}+c_{i}\right)+ \\
+h_{i}\left(\alpha_{i} P_{i}^{2}+\beta_{i} P_{i}+\gamma_{i}\right)
\end{array}\right]+\lambda\left(P_{D}-\sum_{i=1}^{n} P_{i}\right)
\end{gathered}
$$

The solution for the multi-criteria dispatch problem from equation (5), subject to the constraints (21) and (22) with penalty factors (6) or (7) or (8) or (9) or (10) or (11) is transferred to the problem for minimization of $L$ according to $P_{i}, i=\overline{1, n}$, under the constraints (22).

Necessary conditions for optimality for solution of the problem (24), are:

$$
\begin{array}{r}
\text { According to } P_{i}, \frac{\partial L}{\partial P_{i}}=0, i=\overline{1, n} \\
\text { According to } \lambda, \frac{\partial L}{\partial \lambda}=0
\end{array}
$$

Condition (25) is: 


$$
\frac{\partial L}{\partial P_{i}}=2 a_{i} P_{i}+b_{i}+2 h_{i} \alpha_{i} P_{i}+h_{i} \beta_{i}-\lambda=0
$$

The real power $P_{i}$, without valve point effect can be found from the equation (27) as follows:

$$
P_{i}=\frac{\lambda-h_{i} \beta_{i}-b_{i}}{2\left(a_{i}+h_{i} \alpha_{i}\right)}, i=\overline{1, n}
$$

\section{B. Multi-Criteria Dispatch Problem with Valve Point Effect Loading}

The multi-criteria dispatch problem with valve point effect loading is formulated in the following way - find the optimal values of the active power $P_{i}, i=\overline{1, n}$ in such a way that the criterion function (14) is minimized for every type of the price penalty factors (15) to (20) under the constraints (21), (22). The Lagrange's function is determined in the same way as above

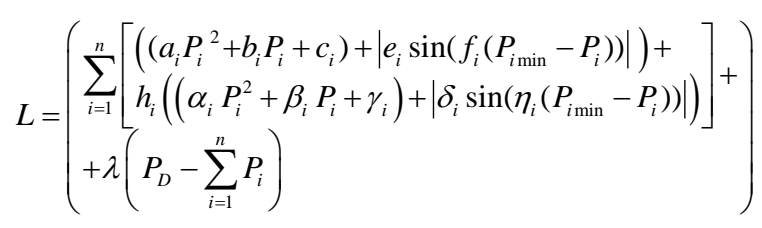

The solution for the multi-criteria dispatch problem (29), subject to the constraints (21) and (22) with penalty factors (15) or (16) or (17) or (18) or (19) or (20) is transferred to the problem for minimization of $L$ according to $P_{i,} i=\overline{1, n}$, under the constraints (22).

The necessary condition for optimality (25) has the following expression

$$
\frac{\partial L}{\partial \mathrm{P}_{i}}=\left[\begin{array}{l}
2\left(a_{i} P_{i}+\alpha_{i} h_{i} P_{i}\right)+b_{i}+\left(h_{i} \beta_{i}\right)+ \\
+\left|-e_{i} f_{i} \cos \left(f_{i}\left(P_{i, \min }-P_{i}\right)\right)\right|+ \\
+\left|\eta_{i} \delta_{i} h_{i}\left(\exp \left(\delta_{i} P_{i}\right)\right)\right|-\lambda
\end{array}\right]
$$

Then the real power $P_{i}$ with valve point effect can be calculated by an iteration procedure starting form a initial values of $P_{i,} i=\overline{1, n}$

$$
\begin{aligned}
& \lambda-b_{i}-\left(h_{i} \beta_{i}\right)-\left|-e_{i} f_{i} \cos \left(f_{i}\left(P_{i, \min }-P_{i}^{(k)}\right)\right)\right| \\
\mathrm{P}_{i}^{(k+1)}= & -\left|\eta_{i} \delta_{i} h_{i}\left(\exp \left(\delta_{i} P_{i}^{(k)}\right)\right)\right|
\end{aligned}
$$

If the value of the Lagrange's multiplier $\lambda$ is known and some initial guess for the values of the active power $P_{i}$ produced by the generators is available, the equation (31) can be solved to determine an updated value of the active power $P_{i}$ with valve point effect.

\section{Algorithm of the Lagrange's Method}

The value of $\lambda$ is unknown and has to be found from the necessary condition for optimality (26)

This condition is found from (24) to be:

$$
\frac{\partial L}{\partial \lambda}=\left(P_{D}-\sum_{i=1}^{n} P_{i}=0=\Delta \lambda\right)
$$

Equation (32) is not a function of $\lambda$, but represents the gradient of $L$ according to $\lambda$. At the optimal solution this gradient has to be equal to zero. As analytical solution is not possible the gradient procedure for calculation of $\lambda$ has to be developed as follows

$$
\lambda^{(k+1)}=\lambda^{k}+\alpha \Delta \lambda^{(k)}, \lambda \neq 0
$$

where

$k$ is the iteration number and,$k=\overline{0: m}$,

$\mathrm{m}$ is the given maximum number of iterations.

$\Delta \lambda^{(k)}$ is determined by the equation (32) and $\alpha$ is the step of the gradient procedure. The calculations start from some given initial value of the Lagrange's variable $\lambda^{(0)}$. When during the iterations $\Delta \lambda=0$, the optimal solution for the Lagrange's variable is obtained. It will determine the optimal solution for the power that has to be produced by the generators.

The obtained solutions for $P_{i}, i=\overline{1, n}$ have to belong to the constraint domain (22). That is why for every step of the gradient procedure, the obtained solution is fit to the constraint domain following the procedure

$$
P_{i}^{(k)}=\left\{\begin{array}{lll}
P_{i, \min }, & \text { if } & P_{i}^{(k)}\left\langle P_{i, \min }\right. \\
P_{i}^{(k)}, & \text { if } & P_{i . \min } \leq P_{i}^{(k)}\left\langle P_{i, \max }\right. \\
P_{i, \max }, & \text { if } & \left.P_{i}^{(k)}\right\rangle P_{i, \max }
\end{array}\right\}
$$

The condition for end of the iteration is

$$
\Delta \lambda^{(k)} \leq \varepsilon
$$

where $\varepsilon>0$ is a small number.

The algorithm of the method is:

1) Initial value of the Lagrange's multiplier is guessed: $\lambda^{(0)}$, and the value of the condition for optimality $\varepsilon$ is given.

2) Initial value of the active power $P_{i}^{0}, i=\overline{1, n}$ is guessed for the case of the dispatch problem with the valve point effect

3) Equation (28) or (31) is solved and $P^{(1)}$ is determined.

4) The obtained vector $P_{i}$ is fit to the constraints (34).

5) $\Delta \lambda^{(0)}$ is calculated using equation (32) where $P^{(1)}$ is substituted.

6) The condition (35) is checked. If it is fulfilled the calculations stop, if not, improved value of $\lambda \rightarrow \lambda^{(1)}$ is calculated using equation (33)

7) Calculations of the improved values of $P_{i} \rightarrow P_{i}^{(2)}$ is done as using equations (28) or (31) with or without valve point effect. Iterations continue until condition (35) is satisfied until the maximum number of iterations $m$ is reached.

8) The optimal solution is used to calculate the total cost, using equations (5), and (14).

The algorithm of the method is shown in Fig. 1. 


\section{Simulation Results of Multi-CRiteria Dispatch PROBLEM}

The five generator system is represented by fuel cost and emission coefficients with valve point effect and real power limits as given in Table I. The problem is formulated as a Multi-objective function using the various penalty factors. The dispatch problem is solved in Matlab environment. The Lagrange's method is used to obtain the solution of the dispatch problem. The solution of the multi-criteria dispatch problem without valve point effect loading is shown in Table II to Table VII for the considered penalty factors (6) to (11). The comparison of the dispatch problem solution for the various penalty factors without valve point effect is shown in Table VIII.

The comparison is done for the maximum power demand of $\mathrm{P}_{\mathrm{D}}=400[\mathrm{MW}]$. Since the bigger variations in the dispatch problem solution exists for maximum power demand. The results show that the fuel cost and emission values are the same for various penalty factors without valve point effect. The Min-Max penalty factor provides minimum fuel cost of combined dispatch problem in compare to other penalty factors. The solution of the multicriteria dispatch problem with valve point effect loading is shown in Table IX to Table XIV for various penalty factors. The comparison of the dispatch problem solution for various penalty factors with valve point effect is shown in Table $\mathrm{XV}$. The results show that Min-Max price penalty factor is good to yield the minimum fuel cost, combined dispatch problem fuel cost, and Computation Time (CT) values of various penalty factors with valve point effect loading. Comparison of the solution with and without valve point effect for the considered penalty factors is shown in Table XVI. The comparison is done on the basis of the Min-Max solution of the dispatch problem with valve point effect of the power demand $\mathrm{P}_{\mathrm{D}} 400$ [MW]. The comparison results show that, there will be smaller variations in the values of the fuel cost, emission, combined fuel cost and computation time in comparison to the solution without valve point effect.

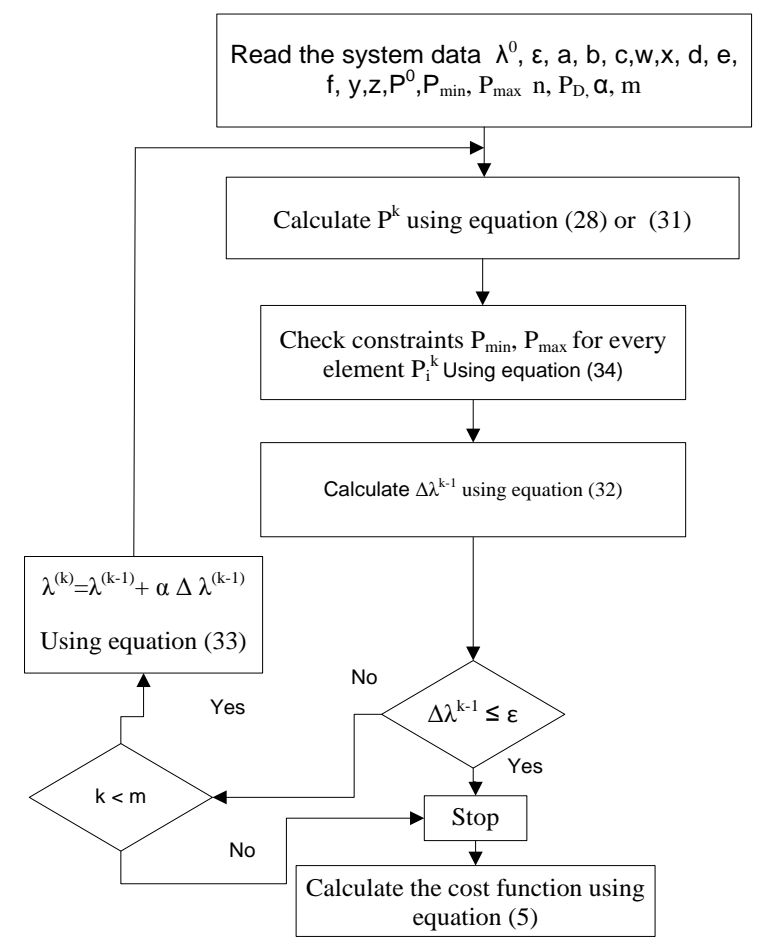

Fig. 1. Flow diagram of multi-criteria dispatch problem with valve point effect using Lagrange's method

TABle i: Data of the Multi-Criteria Dispatch Problem Data of FiVe Generator System

\begin{tabular}{|c|c|c|c|c|c|c|}
\hline \multicolumn{2}{|l|}{ Generator } & 1 & 2 & 3 & 4 & 5 \\
\hline \multirow{5}{*}{$\begin{array}{l}\text { Fuel cost } \\
\text { coefficients and } \\
\text { valve point effect } \\
\text { coefficients }\end{array}$} & $a_{i}$ & 25 & 60 & 100 & 120 & 40 \\
\hline & $b_{i}$ & 2.0 & 1.8 & 2.1 & 2.0 & 1.8 \\
\hline & $c_{i}$ & 0.0080 & 0.0030 & 0.0012 & 0.0010 & 0.0015 \\
\hline & $e_{i}$ & 100 & 140 & 160 & 180 & 200 \\
\hline & $f_{i}$ & 0.0042 & 0.040 & 0.038 & 0.037 & 0.035 \\
\hline \multirow{5}{*}{$\begin{array}{l}\text { Emission } \\
\text { coefficients and } \\
\text { valve point effect } \\
\text { coefficients }\end{array}$} & $\alpha_{i}$ & 80 & 50 & 60 & 45 & 30 \\
\hline & $\beta_{i}$ & -0.805 & -0.555 & -1.355 & -0.600 & -0.555 \\
\hline & $\gamma_{\mathrm{i}}$ & 0.0180 & 0.0150 & 0.0105 & 0.0080 & 0.0120 \\
\hline & $\delta_{\mathrm{i}}$ & 0.6550 & 0.5773 & 0.4968 & 0.4860 & 0.5035 \\
\hline & $\eta_{\mathrm{i}}$ & 0.02846 & 0.02446 & 0.02270 & 0.01948 & 0.02075 \\
\hline \multirow{2}{*}{$\begin{array}{l}\text { Generator real } \\
\text { power } \\
\text { operational limits }\end{array}$} & $\mathrm{P}_{\mathrm{i}, \min }$ & 10 & 20 & 30 & 40 & 50 \\
\hline & $\mathrm{P}_{\mathrm{i}, \max }$ & 75 & 125 & 175 & 250 & 300 \\
\hline
\end{tabular}


TABLE II: Multi-Criteria Dispatch Problem Solution Using Min-Max Price Penalty Factor Without Valve Point EFFect

\begin{tabular}{|l|l|l|l|l|l|l|l|l|l|l|}
\hline $\mathrm{P}_{\mathrm{D}}$ & lambda & $\mathrm{P} 1$ & $\mathrm{P} 2$ & $\mathrm{P} 3$ & $\mathrm{P} 4$ & $\mathrm{P} 5$ & $\mathrm{~F}_{\mathrm{C}}$ & $\mathrm{E}_{\mathrm{T}}$ & $\mathrm{F}_{\mathrm{T}}$ & $\mathrm{CT}$ \\
\hline 200 & 38.633 & 36.633 & 36.833 & 36.534 & 40.000 & 50.000 & 540807.100 & 402124.600 & 555113.266 & 3.428 \\
\hline 250 & 51.940 & 49.940 & 50.140 & 49.840 & 49.940 & 50.140 & 861920.600 & 661720.000 & 884665.550 & 3.530 \\
\hline 300 & 61.940 & 59.940 & 60.140 & 59.840 & 59.940 & 60.140 & 1241304.000 & 953063.200 & 1274065.637 & 3.331 \\
\hline 350 & 71.940 & 69.940 & 70.140 & 69.840 & 69.940 & 70.140 & 1689687.000 & 1297406.000 & 1734288.392 & 3.176 \\
\hline 400 & 81.940 & 79.940 & 80.140 & 79.840 & 79.940 & 80.140 & 2207070.000 & 1694750.000 & 2265333.814 & 3.064 \\
\hline
\end{tabular}

TABLE III: Multi-Criteria DisPatch Problem Solution Using MaX-Max Price Penalty Factor Without Valve Point EFFECT

\begin{tabular}{|l|l|l|l|l|l|l|l|l|l|l|}
\hline $\mathrm{P}_{\mathrm{D}}$ & lambda & $\mathrm{P} 1$ & $\mathrm{P} 2$ & $\mathrm{P} 3$ & $\mathrm{P} 4$ & $\mathrm{P} 5$ & $\mathrm{~F}_{\mathrm{C}}$ & $\mathrm{E}_{\mathrm{T}}$ & $\mathrm{F}_{\mathrm{T}}$ & $\mathrm{CT}$ \\
\hline 200 & 38.630 & 36.632 & 36.833 & 36.535 & 40.000 & 50.000 & 540815.100 & 402123.700 & 1081171.254 & 3.482 \\
\hline 250 & 51.936 & 49.939 & 50.139 & 49.842 & 49.940 & 50.141 & 861927.400 & 661716.800 & 1723337.987 & 3.920 \\
\hline 300 & 61.936 & 59.939 & 60.139 & 59.842 & 59.940 & 60.141 & 1241312.000 & 953059.500 & 2482062.049 & 3.186 \\
\hline 350 & 71.936 & 69.939 & 70.139 & 69.842 & 69.940 & 70.141 & 1689696.000 & 1297402.000 & 3378805.616 & 3.467 \\
\hline 400 & 81.936 & 79.939 & 80.139 & 79.842 & 79.940 & 80.141 & 2207081.000 & 1694745.000 & 4413568.689 & 3.348 \\
\hline
\end{tabular}

TABLE IV: Multi-Criteria DisPatch Problem Solution Using Min-Min Price Penalty Factor Without Valve Point EFFeCt

\begin{tabular}{|l|l|l|l|l|l|l|l|l|l|l|}
\hline $\mathrm{P}_{\mathrm{D}}$ & lambda & $\mathrm{P} 1$ & $\mathrm{P} 2$ & $\mathrm{P} 3$ & $\mathrm{P} 4$ & $\mathrm{P} 5$ & $\mathrm{~F}_{\mathrm{C}}$ & $\mathrm{E}_{\mathrm{T}}$ & $\mathrm{f}_{\mathrm{t}}$ & $\mathrm{CT}$ \\
\hline 200 & 38.630 & 36.632 & 36.833 & 36.535 & 40.000 & 50.000 & 540815.100 & 402123.700 & 1081961.310 & 3.118 \\
\hline 250 & 51.936 & 49.939 & 50.139 & 49.842 & 49.940 & 50.141 & 861927.400 & 661716.900 & 1724679.537 & 3.122 \\
\hline 300 & 61.936 & 59.939 & 60.139 & 59.842 & 59.940 & 60.141 & 1241312.000 & 953059.500 & 2483994.351 & 3.131 \\
\hline 350 & 71.936 & 69.939 & 70.139 & 69.842 & 69.940 & 70.141 & 1689696.000 & 1297402.000 & 3381436.153 & 3.224 \\
\hline 400 & 81.936 & 79.939 & 80.139 & 79.842 & 79.940 & 80.141 & 2207081.000 & 1694745.000 & 4417004.942 & 2.990 \\
\hline
\end{tabular}

TABle V: Multi-Criteria Dispatch Problem Solution Using MaX-Min Price Penalty factor Without Valve Point EfFect

\begin{tabular}{|l|l|l|l|l|l|l|l|l|l|l|}
\hline $\mathrm{P}_{\mathrm{D}}$ & lambda & $\mathrm{P} 1$ & $\mathrm{P} 2$ & $\mathrm{P} 3$ & $\mathrm{P} 4$ & $\mathrm{P} 5$ & $\mathrm{~F}_{\mathrm{C}}$ & $\mathrm{E}_{\mathrm{T}}$ & $\mathrm{F}_{\mathrm{T}}$ & $\mathrm{CT}$ \\
\hline 200 & 38.626 & 36.631 & 36.832 & 36.537 & 40.000 & 50.000 & 540823.200 & 402122.700 & 21257001.400 & 3.361 \\
\hline 250 & 51.933 & 49.938 & 50.138 & 49.844 & 49.939 & 50.142 & 861934.300 & 661713.700 & 34040621.700 & 3.336 \\
\hline 300 & 61.933 & 59.938 & 60.138 & 59.844 & 59.939 & 60.142 & 1241320.000 & 953055.700 & 49030097.010 & 2.958 \\
\hline 350 & 71.933 & 69.938 & 70.138 & 69.844 & 69.939 & 70.142 & 1689706.000 & 1297398.000 & 66746702.440 & 3.227 \\
\hline 400 & 81.933 & 79.938 & 80.138 & 79.844 & 79.939 & 80.142 & 2207092.000 & 1694740.000 & 87190438.000 & 3.069 \\
\hline
\end{tabular}

table Vi: Multi-Criteria Dispatch Problem Solution Using Average Price Penalty Factor Without Valve Point EfFect

\begin{tabular}{|l|l|l|l|l|l|l|l|l|l|l|}
\hline $\mathrm{P}_{\mathrm{D}}$ & lambda & $\mathrm{P} 1$ & $\mathrm{P} 2$ & $\mathrm{P} 3$ & $\mathrm{P} 4$ & $\mathrm{P} 5$ & $\mathrm{~F}_{\mathrm{C}}$ & $\mathrm{E}_{\mathrm{T}}$ & $\mathrm{F}_{\mathrm{T}}$ & $\mathrm{CT}$ \\
\hline 200 & 38.627 & 36.631 & 36.832 & 36.537 & 40.000 & 50.000 & 540821.600 & 402123.000 & 5993811.195 & 3.562 \\
\hline 250 & 51.933 & 49.938 & 50.138 & 49.843 & 49.939 & 50.142 & 861932.800 & 661714.400 & 9593327.149 & 3.020 \\
\hline 300 & 61.933 & 59.938 & 60.138 & 59.843 & 59.939 & 60.142 & 1241318.000 & 953056.600 & 13817555.910 & 3.346 \\
\hline 350 & 71.933 & 69.938 & 70.138 & 69.843 & 69.939 & 70.142 & 1689704.000 & 1297399.000 & 18810309.480 & 3.235 \\
\hline 400 & 81.933 & 79.938 & 80.138 & 79.843 & 79.939 & 80.142 & 2207090.000 & 1694741.000 & 24571587.880 & 3.208 \\
\hline
\end{tabular}


TABLE VII: Multi-Criteria Dispatch Problem SOlution Using Common Price Penalty Factor Without Valve Point EFFect

\begin{tabular}{|l|l|l|l|l|l|l|l|l|l|l|}
\hline $\mathrm{P}_{\mathrm{D}}$ & lambda & $\mathrm{P} 1$ & $\mathrm{P} 2$ & $\mathrm{P} 3$ & $\mathrm{P} 4$ & $\mathrm{P} 5$ & $\mathrm{~F}_{\mathrm{C}}$ & $\mathrm{E}_{\mathrm{T}}$ & $\mathrm{F}_{\mathrm{T}}$ & $\mathrm{CT}$ \\
\hline 200 & 38.628 & 36.632 & 36.832 & 36.536 & 40.000 & 50.000 & 540816.200 & 402123.900 & 1631406.497 & 3.190 \\
\hline 250 & 51.935 & 49.939 & 50.139 & 49.842 & 49.939 & 50.141 & 861927.900 & 661716.800 & 2608201.405 & 3.236 \\
\hline 300 & 61.935 & 59.939 & 60.139 & 59.842 & 59.939 & 60.141 & 1241312.000 & 953059.400 & 3756553.552 & 3.297 \\
\hline 350 & 71.935 & 69.939 & 70.139 & 69.842 & 69.939 & 70.141 & 1689697.000 & 1297402.000 & 5113810.663 & 3.312 \\
\hline 400 & 81.935 & 79.939 & 80.139 & 79.842 & 79.939 & 80.141 & 2207082.000 & 1694745.000 & 6679972.739 & 3.130 \\
\hline
\end{tabular}

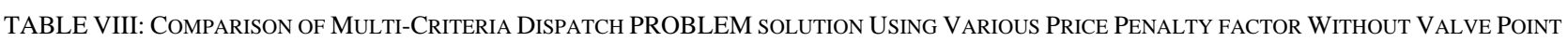
EFFECT LOADING

\begin{tabular}{|l|l|l|l|l|l|l|}
\hline \multirow{2}{*}{ Criterion } & \multicolumn{5}{|l}{ Impact of various penalty factors of multi-criteria dispatch problem solution without valve point effect loading when $\mathrm{P}_{\mathrm{D}}=400[\mathrm{MW}]$} \\
\cline { 2 - 7 } & Min-Max & Max-Max & Min-Min & Max-Min & Average & Common \\
\hline $\mathrm{F}_{\mathrm{C}}$ & $100 \%$ & $100 \%$ & $100 \%$ & $100 \%$ & $100 \%$ & $100 \%$ \\
\hline $\mathrm{E}_{\mathrm{T}}$ & $100 \%$ & $99.99 \%$ & $99.99 \%$ & $99.99 \%$ & $100 \%$ & $100 \%$ \\
\hline $\mathrm{F}_{\mathrm{T}}$ & $100 \%$ & $194.83 \%$ & $194.98 \%$ & $3848.90 \%$ & $1084.67 \%$ & $294.87 \%$ \\
\hline $\mathrm{CT}$ & $100 \%$ & $109.26 \%$ & $97.58 \%$ & $100.16 \%$ & $104.70 \%$ & $102.15 \%$ \\
\hline
\end{tabular}

TABle IX: Multi-Criteria Dispatch Problem Solution Using Min-Max Price Penalty Factor with Valve Point EFFect Loading

\begin{tabular}{|l|l|l|l|l|l|l|l|l|l|l|}
\hline $\mathrm{P}_{\mathrm{D}}$ & lambda & $\mathrm{P} 1$ & $\mathrm{P} 2$ & $\mathrm{P} 3$ & $\mathrm{P} 4$ & $\mathrm{P} 5$ & $\mathrm{~F}_{\mathrm{CVP}}$ & $\mathrm{E}_{\mathrm{TVP}}$ & $\mathrm{F}_{\mathrm{TVP}}$ & $\mathrm{CT}$ \\
\hline 200 & 42.559 & 39.135 & 36.329 & 34.536 & 40.000 & 50.000 & 529342.332 & 406934.633 & 543259.496 & 3.305 \\
\hline 250 & 55.332 & 52.452 & 51.928 & 48.689 & 46.931 & 50.000 & 832799.182 & 671089.805 & 854695.480 & 3.469 \\
\hline 300 & 65.390 & 61.108 & 62.816 & 61.038 & 58.230 & 56.809 & 1239748.925 & 968739.646 & 1272452.037 & 3.164 \\
\hline 350 & 74.876 & 69.516 & 70.634 & 72.560 & 69.943 & 67.347 & 1716417.407 & 1307904.172 & 1761812.973 & 3.463 \\
\hline 400 & 84.670 & 78.615 & 78.924 & 80.551 & 82.660 & 79.249 & 2249640.856 & 1690782.844 & 2309050.367 & 3.644 \\
\hline
\end{tabular}

TABle X: Multi-Criteria Dispatch Problem Solution Using MaX-MaX Price Penalty Factor with Valve Point EFFect LoAding

\begin{tabular}{|l|l|l|l|l|l|l|l|l|l|l|}
\hline $\mathrm{P}_{\mathrm{D}}$ & lambda & $\mathrm{P} 1$ & $\mathrm{P} 2$ & $\mathrm{P} 3$ & $\mathrm{P} 4$ & $\mathrm{P} 5$ & $\mathrm{~F}_{\mathrm{CVP}}$ & $\mathrm{E}_{\mathrm{TVP}}$ & $\mathrm{F}_{\mathrm{TVP}}$ & $\mathrm{CT}$ \\
\hline 200 & 41.577 & 38.254 & 35.943 & 35.803 & 40.000 & 50.000 & 534878.984 & 405432.080 & 1069099.537 & 3.543 \\
\hline 250 & 54.122 & 51.631 & 51.215 & 49.850 & 47.304 & 50.000 & 841917.474 & 669022.407 & 1682947.109 & 3.133 \\
\hline 300 & 64.209 & 60.296 & 62.380 & 62.327 & 58.677 & 56.320 & 1253988.402 & 968360.420 & 2506900.424 & 3.139 \\
\hline 350 & 73.798 & 68.766 & 70.277 & 73.465 & 70.561 & 66.931 & 1732214.801 & 1307253.243 & 3463235.175 & 3.201 \\
\hline 400 & 83.659 & 77.886 & 78.612 & 81.523 & 83.100 & 78.880 & 2265987.107 & 1690162.676 & 4530767.379 & 2.975 \\
\hline
\end{tabular}

TABle Xi: Multi-Criteria Dispatch Problem Solution Using Min-Min Price Penalty Factor with Valve Point EFFect Loading

\begin{tabular}{|l|l|l|l|l|l|l|l|l|l|l|}
\hline $\mathrm{P}_{\mathrm{D}}$ & lambda & $\mathrm{P} 1$ & $\mathrm{P} 2$ & $\mathrm{P} 3$ & $\mathrm{P} 4$ & $\mathrm{P} 5$ & $\mathrm{~F}_{\mathrm{CVP}}$ & $\mathrm{E}_{\mathrm{TVP}}$ & $\mathrm{F}_{\mathrm{TVP}}$ & $\mathrm{CT}$ \\
\hline 200 & 41.575 & 38.254 & 35.942 & 35.803 & 40.000 & 50.000 & 534881.255 & 405432.799 & 1069904.824 & 4.199 \\
\hline 250 & 54.120 & 51.632 & 51.214 & 49.851 & 47.303 & 50.000 & 841917.450 & 669024.799 & 1684313.711 & 3.290 \\
\hline 300 & 64.208 & 60.296 & 62.380 & 62.328 & 58.677 & 56.319 & 1253992.305 & 968366.430 & 2508883.901 & 3.037 \\
\hline 350 & 73.796 & 68.767 & 70.277 & 73.466 & 70.560 & 66.930 & 1732216.638 & 1307259.655 & 3465890.285 & 4.192 \\
\hline 400 & 83.657 & 77.887 & 78.611 & 81.524 & 83.099 & 78.880 & 2265990.399 & 1690169.675 & 4534185.116 & 2.987 \\
\hline
\end{tabular}


TABLE XII: Multi-Criteria DisPatch Problem Solution Using MaX-Min Price Penalty Factor with Valve Point EFFeCt LOADING

\begin{tabular}{|l|l|l|l|l|l|l|l|l|l|l|}
\hline $\mathrm{P}_{\mathrm{D}}$ & lambda & $\mathrm{P} 1$ & $\mathrm{P} 2$ & $\mathrm{P} 3$ & $\mathrm{P} 4$ & $\mathrm{P} 5$ & $\mathrm{~F}_{\mathrm{CVP}}$ & $\mathrm{E}_{\mathrm{TVP}}$ & $\mathrm{F}_{\mathrm{TVP}}$ & CT \\
\hline 200 & -4.418 & 10.000 & 20.000 & 70.112 & 49.888 & 50.000 & 917344.439 & 509774.132 & 34000867.870 & 3.099 \\
\hline 250 & 10.832 & 19.116 & 29.902 & 83.031 & 67.952 & 50.000 & 1407173.883 & 770167.185 & 52741433.690 & 3.258 \\
\hline 300 & 22.160 & 31.777 & 43.004 & 92.580 & 82.639 & 50.000 & 1913887.634 & 1069586.977 & 72477586.370 & 3.090 \\
\hline 350 & 33.804 & 45.680 & 57.685 & 102.947 & 92.020 & 51.669 & 2435689.054 & 1430045.275 & 92813282.970 & 4.119 \\
\hline 400 & 44.612 & 55.406 & 67.119 & 113.346 & 100.930 & 63.199 & 3015215.214 & 1819592.900 & 115169251.900 & 3.279 \\
\hline
\end{tabular}

TABle XIII: Multi-Criteria Dispatch Problem Solution Using Average Price Penalty Factor with Valve Point EFFECt LOADING

\begin{tabular}{|l|l|l|l|l|l|l|l|l|l|l|}
\hline $\mathrm{P}_{\mathrm{D}}$ & lambda & $\mathrm{P} 1$ & $\mathrm{P} 2$ & $\mathrm{P} 3$ & $\mathrm{P} 4$ & $\mathrm{P} 5$ & $\mathrm{~F}_{\mathrm{CVP}}$ & $\mathrm{E}_{\mathrm{TVP}}$ & $\mathrm{F}_{\mathrm{TVP}}$ & $\mathrm{CT}$ \\
\hline 200 & 32.440 & 31.514 & 32.581 & 45.683 & 40.222 & 50.000 & 591979.226 & 405393.643 & 6436098.261 & 3.536 \\
\hline 250 & 43.232 & 44.371 & 45.312 & 58.698 & 51.620 & 50.000 & 937620.470 & 661601.586 & 10265336.050 & 3.088 \\
\hline 300 & 53.600 & 54.105 & 58.466 & 71.774 & 63.802 & 51.853 & 1390591.190 & 977804.790 & 15254576.340 & 3.202 \\
\hline 350 & 63.855 & 62.972 & 67.162 & 80.135 & 76.949 & 62.782 & 1881452.548 & 1312504.047 & 20702177.490 & 3.317 \\
\hline 400 & 74.382 & 72.410 & 75.961 & 88.894 & 87.570 & 75.164 & 2415116.064 & 1696370.162 & 26618980.110 & 3.217 \\
\hline
\end{tabular}

TABle XIV: Multi-Criteria Dispatch Problem Solution Using Common Price Penalty FaCtor With VAlve Point EFFeCt LOADiNG

\begin{tabular}{|l|l|l|l|l|l|l|l|l|l|l|}
\hline $\mathrm{P}_{\mathrm{D}}$ & lambda & $\mathrm{P} 1$ & $\mathrm{P} 2$ & $\mathrm{P} 3$ & $\mathrm{P} 4$ & $\mathrm{P} 5$ & $\mathrm{~F}_{\mathrm{CVP}}$ & $\mathrm{E}_{\mathrm{TVP}}$ & $\mathrm{F}_{\mathrm{TVP}}$ & $\mathrm{CT}$ \\
\hline 200 & 40.605 & 37.670 & 35.634 & 36.696 & 40.000 & 50.000 & 538920.898 & 404663.250 & 1626562.659 & 3.252 \\
\hline 250 & 52.918 & 51.017 & 50.580 & 50.580 & 47.824 & 50.000 & 849728.563 & 667366.296 & 2570728.181 & 3.222 \\
\hline 300 & 63.052 & 59.710 & 62.009 & 63.170 & 59.309 & 55.803 & 1266658.237 & 968384.780 & 3825134.854 & 3.404 \\
\hline 350 & 72.707 & 68.219 & 69.955 & 74.055 & 71.331 & 66.442 & 1746822.719 & 1307167.892 & 5269826.767 & 4.107 \\
\hline 400 & 82.646 & 77.382 & 78.345 & 82.185 & 83.642 & 78.446 & 2280483.270 & 1690340.038 & 6886389.421 & 3.118 \\
\hline
\end{tabular}

TABLE XV: Comparison of Multi-Criteria Dispatch Problem Solution Using Various Price Penalty Factor with Valve Point EFFeCt LOADING

\begin{tabular}{|l|l|l|l|l|l|l|}
\hline \multirow{2}{*}{ Criterion } & \multicolumn{5}{|l|}{ Impact of various penalty factors of multi-criteria dispatch problem solution with valve point effect loading } \\
\cline { 2 - 7 } & Min-Max & Max-Max & Min-Min & Max-Min & Average & Common \\
\hline $\mathrm{F}_{\mathrm{CVP}}$ & $100 \%$ & $100.72 \%$ & $100.72 \%$ & $134.03 \%$ & $107.35 \%$ & $101.37 \%$ \\
\hline $\mathrm{E}_{\mathrm{TVP}}$ & $100 \%$ & $99.96 \%$ & $99.96 \%$ & $107.61 \%$ & $100.33 \%$ & $99.97 \%$ \\
\hline $\mathrm{F}_{\mathrm{TVP}}$ & $100 \%$ & $196.21 \%$ & $196.36 \%$ & $4987.73 \%$ & $1152.81 \%$ & $298.23 \%$ \\
\hline $\mathrm{CT}_{\mathrm{VP}}$ & $100 \%$ & $81.64 \%$ & $81.97 \%$ & $89.96 \%$ & $88.28 \%$ & $85.56 \%$ \\
\hline
\end{tabular}

TABLE XVI: Comparison OF Multi-Criteria Dispatch Problem Solution Using VARious Price Penalty Factor For the CASES With AND Without Vivalve Point EFFECT LOADING

\begin{tabular}{|l|l|l|l|l|l|l|}
\hline Criterion comparison & Min-Max & Max-Max & Min-Min & Max-Min & Average & Common \\
\hline $\mathrm{F}_{\mathrm{C}} \mathrm{Vs} \mathrm{F}_{\mathrm{CVP}}$ & $0 \%$ & $0.72 \%$ & $0.72 \%$ & $34.03 \%$ & $7.35 \%$ & $1.37 \%$ \\
\hline $\mathrm{E}_{\mathrm{T}} \mathrm{Vs} \mathrm{E}_{\mathrm{TVP}}$ & $0 \%$ & $-0.03 \%$ & $-0.03 \%$ & $7.62 \%$ & $0.33 \%$ & $0.03 \%$ \\
\hline $\mathrm{F}_{\mathrm{T}} \mathrm{Vs} \mathrm{F}_{\mathrm{TVP}}$ & $0 \%$ & $0.62 \%$ & $1.38 \%$ & $1138.83 \%$ & $68.14 \%$ & $3.36 \%$ \\
\hline $\mathrm{CT} \mathrm{Vs}_{\mathrm{VP}}$ & $0 \%$ & $-27.62 \%$ & $-15.61 \%$ & -11.20 & $-16.5 \%$ & $-16.59 \%$ \\
\hline
\end{tabular}




\section{CONCLUSION}

The multi-criteria dispatch problem of both fuel cost function and emission function are formulated without and with valve point effect loading. The Lagrange's algorithm is developed for the solution of the dispatch problem. The five generator multi-objective dispatch problem is solved separately with and without valve point effect for various price penalty factors such as i)Min-Max ii) Max-Max, iii)Min-Min, iv)Max-Min, v)Average, and v) Common. It concludes that Min-Max price penalty factor is good to yield the minimum fuel cost, and combined dispatch problem fuel cost values in comparison to other penalty factors. The comparison results of the solution of the dispatch problem with and without valve point effect show that, there exist smaller variations in fuel cost, emission, combined fuel cost, and computation time.

\section{ACKNOWLEDGEMENT}

The authors gratefully acknowledge the authorities of Cape Peninsula University of Technology, South Africa for the facilities offered to carry out this work. The research work is funded by the National research foundation (NRF) grant UID62364 "Substation Automation and Energy Management Systems".

\section{REFERENCES}

[1] S. Hemamalini and S. P. Simon, "Dynamic Economic Dispatch with Valve-Point Effect Using Maclaurin Series Based Lagrangian Method," International Journal of Computer Applications, 2010, vol. 1, no. 17, pp. 60-67.

[2] S. Hemamalini and S. P. Simon, "Maclaurin series-based Lagrangian method for economic dispatch with valve-point effect," IET Gener. Transm. Distrib, 2009, vol. 3, no. 9, pp. 859-871.

[3] T. Ratniyomchai, A. Oonsivilai, P. P. L. Or, and T. Kulworawanichpong, "Economic Load Dispatch Using Improved Harmony Search," WSEAS Transactions on Systems and Control, vol. 5, April 2010, pp. 248-257.

[4] S. Tiacharoen, S. Potiya, and P. Polratanasuk, "Solving various types of economic dispatch problem using Bees algorithm," International Conference on Electrical Engineering/Electronics Computer Telecommunications and Information Technology (ECTI-CON), May 2010, pp. $617-620$.

[5] L. L. Lai, T. Y. Nieh, D. Vujatovic, Y. N. Ma, Y. P. Lu, Y, W. Wang, and H. Braun, "Particle swarm optimization for economic dispatch of units with non-smooth input-output characteristic functions," in Proceedings of the 13th International Conference on Intelligent Systems Application to Power Systems, pp. 6-10 Nov. 2005.

[6] J. B. Park, K. S. Lee, J. R. Shin, and K. Y. Lee, "A Particle Swarm Optimization for Economic Dispatch With Non smooth Cost Functions," IEEE Transactions on Power Systems, vol. 20, no. 1, February 2005.

[7] J. B. Park, Y. W. Jeong, J. R. Shin, and K. Y. Lee, "An Improved Particle Swarm Optimization for Nonconve Economic Dispatch Problems," IEEE Transactions on Power Systems, vol. 25, no. 1, 2010.

[8] L. D. S. Coelho and V. C. Mariani, "Economic dispatch optimization using hybrid chaotic particle swarm optimizer," International Conference on Systems, Man and Cybernetics, Oct, 2007, Montreal, pp. $1963-1968$.

[9] Z. Tao and C. J. Ding, "A new chaotic PSO with dynamic inertia weight for economic dispatch problem," International Conference on Sustainable Power Generation and Supply, 2009, Nanjing, pp. 1 - 6.

[10] K. Meng, H. G. Wang, Z. Y. Dong, and K. P. Wong, "QuantumInspired Particle Swarm Optimization for Valve-Point Economic Load Dispatch," IEEE Transactions on Power Systems, vol. 25, no. 1, February 2010, pp. 215-222.

[11] V. Hosseinnezhad, M. T. Hagh, and E. Babaei, "Quantum particle swarm optimization for economic dispatch problem with valve-point effect," 19th Iranian Conference on Electrical Engineering (ICEE), pp. 17-19, May 2011.

[12] W. N. Lee, Y. W. Jeong, J. B. Park, J. R. Shin, and K. Y. Lee, "Development of an Educational Simulator for Particle Swarm Optimization and Economic Dispatch Applications," Conference on Intelligent Systems Applications to Power Systems, ISAP, Toki Messe, Niigata , 5-8 Nov. 2007, pp. 1-6.

[13] W. Sugsakarn and P. Damrongkulkamjorn, "Economic Dispatch with Nonsmooth Cost function using Hybrid Method," in Proceedings of ECTI-CON, 2008, pp. 889-892.

[14] M. T. Tsai and C. W. Yen, "An Improved Particle Swarm Optimization for Economic Dispatch with Carbon Tax Considerations," International Conference on Power System Technology, 2010, pp 1-6.

[15] Z. Ming, L. Xiaotong, Y. Fan, and T. Kuo, "The multi-objective optimization model of energy-efficient scheduling based on PSO algorithm," Asia-Pacific, Power and Energy Engineering Conference (APPEEC), Chengdu, 2010 , pp. 1-4.

[16] J. S. Alsumait, M. Qasem, J. K. Sykulski, and A. K. A. Othman, "An Improved pattern search based algorithm to solve the dynamic economic dispatch problem with valve-point effect," Energy Conversion and Management, 2010.

[17] C. Rani, M. Rajesh Kumar, and K. Pavan, "Multi-Objective Generation Dispatch using Particle Swarm Optimization," in Proceedings of India International Conference on Power Electronics, 2006, pp. 421-424.

[18] D. N. Jeyakumar, T. Jayabarathi, and T. Raghunathan, "Particle swarm optimization for various types of economic dispatch problems," Electrical Power and Energy Systems, vol. 28, 2006, pp. $36-42$.

[19] D. N. Jeyakumar, P. Venkatesh, and K. Y. Lee, "Application of Multi Objective Evolutionary Programming to Combined Economic Emission Dispatch Problem," in Proceedings of International Joint Conference on Neural Networks, Orlando, Florida, USA, August 1217, 2007.

[20] R. Balamurugan and S. Subramanian, "A Simplified Re-cursive Approach to Combined Economic Emission Dis-patch," Electric Power Components and Systems, vol. 36, no. 1, 2008, pp. 17-27.

[21] R. M. S. Danaraj and F. Gajendran, "Quadratic Programming Solution to Emission and Economic Dispatch Prob-lems," Journal of Institution of Engineers (India), vol. 86, 2005, pp. 129-132.

[22] S. P. Karthikeyan, K. Palanisamy, C. Rani, I. J. Raglen, and D. P. Kothari, "Security constrained unit commitment problem with operational Power flow and environmental constraints," WSEAS Transactions on Power Systems, vol. 4, no. 4, 2009, pp. 53-56.

[23] S. Subramanian and S. Ganesan, "Sequential Approach with Matrix Framework for Various Types of Economic Thermal Power Dispatch Problems," Energy and Power Engineering, 2010, vol. 2, pp. 111121.

[24] T. Thakur, K. Sem, S. Saini, and S. Sharma, "A Particle Swarm Optimization Solution to $\mathrm{NO} 2$ and $\mathrm{SO} 2$ Emissions for Environmentally Constrained Economic Dispatch Problem," IEEE/PES, Transmission and Distribution Conference and Exposition, Latin America, 2006.

[25] P. S. Kulkarni, A. G. Kothari, and D. P. Kothari, "Combined Economic and Emission Dispatch using Improved Back Propagation Neural Network," Int. Jour. of Electrical Machines and Power Systems, 2000, vol. 28, pp. 31-44.

[26] S. Krishnamurthy and R. Tzoneva, "Comparative Analyses of MinMax and Max-Max Price Penalty Factor Approaches for Multi Criteria Power System Dispatch Problem Using Lagrange's Method," International conference on recent advancements in Electrical, Electronics and Control Engineering, Sivakasi, India, 15th-17th December 2011.

[27] S. Krishnamurthy and R. Tzoneva, "Comparative Analyses of MinMax and Max-Max Price Penalty Factor Approaches for Multi Criteria Power System Dispatch Problem with Valve Point Effect Loading Using Lagrange's Method," International conference on International Conference on Power and Energy Systems, Chennai, India, 22nd -24th December 2011.

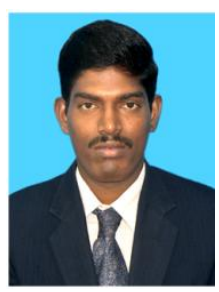

Senthil Krishnamurthy received the Master of Engineering in Power Systems from the Faculty of Engineering \& Technology, Annamalai University, and Chidambaram, India in 2008. Currently, he is pursing Doctorate Technology in the Electrical Engineering Department, Cape Peninsula university of Technology, South Africa. His areas of research include Energy Management System, Power System Optimization, Particle Swarm Optimization, Clusters 
of Computers, Parallel Computation and Real Time Digital Simulator. He is a graduate student member of Institution of Electrical and Electronics Engineers (IEEE), Member of Institution of Engineers India (IEI), Member of Indian Society for Technical Education (MISTE), Institution of Engineers Tanzania (IET) and Kenyan Society of Electrical and Electronics Engineers (KSEEE).

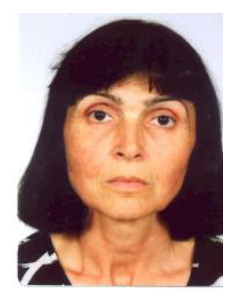

Raynitchka Tzoneva has MSc and $\mathrm{PhD}$ in Electrical Engineering (control specialization) from the Technical University of Sofia (TUS), Bulgaria. She has been a lecturer at the TUS and an Associated Professor at the Bulgarian Academy of Sciences, Institute of Information Technologies between 1982 and 1997. Since 1998 she has been working as a Professor at the Department of Electrical Engineering, Cape Peninsula University of Technology, Cape Town. R. Tzoneva is a leader of the Niche area Real Time Distributed Systems (RTDS) and of the Centre for Substation Automation and Energy management Systems supported by the South African Research Foundation (NRF). R. Tzoneva is a member of the Institute of Electrical and Electronic Engineers (IEEE). Her research interest is in the fields of optimal and robust control design and optimization of linear and nonlinear systems, energy management systems, real-time digital simulations, and parallel computation. 